\title{
Analysis of Load Variation Consideration for Optimal Distributed Generation Placement
}

\author{
Aida Fazliana Abdul Kadir ${ }^{1}$, Mohamad Fani Sulaima ${ }^{2}$, Noor Ropidah Bujal ${ }^{3}$ \\ Mohd Nazri Bin Abd Halim ${ }^{4}$, Elia Erwani Hassan ${ }^{5}$ \\ Faculty of Electrical Engineering, University Teknikal Malaysia Melaka \\ Melaka, Malaysia
}

\begin{abstract}
Distributed generation (DG) devices offered usefully for power losses minimization, grid reinforcement, bus voltages improvement and efficiency of a distribution system. Usually, the DG placement problem considers the predefined DG number and sizes that might result in many small DGs. However, a better solution could be reached with a minimum number of DGs, reducing installation and maintenance costs. Furthermore, the increment of load and vice versa may affect the voltage profile below or upper the tolerable limit and distribution feeders. Thus, this paper aims to analyze the impact of the variation of the load level with the DG connection in the power system by using the improved gravitational search algorithm (IGSA) as an optimization technique. The multi-objective function target reduces the total power loss, average total voltage harmonic distortion and voltage deviation in the distribution system. This study is considering six different load levels as in percentage of load. This proposed technique compares with the particle swarm optimization (PSO) and the gravitational search algorithm (GSA). This efficiency of the proposed technique tests on the 33-bus radial distribution system with six case studies.
\end{abstract}

Keywords-Distribution generation; optimization techniques; IGSA; losses minimization; optimal placement and sizing

\section{INTRODUCTION}

Distributed generation is a technology that generates electricity at or near to the load center by using renewable energy to produce electricity [1]. DG may provide a single structure for a residential and business, but also can be section of a microgrid. DG usually applied in industrial facilities, military base to the provided power supply, or a large university. In other terms, DG could be "electric power generation within distribution networks or on the customer side of the network" [2]. DG technologies that usually available in Malaysia is solar photovoltaic, wind power, biomass, and solar thermal systems. Nowadays, people want the energy that purifier and have less impact on the environment. They tend to pick DG as main electricity supply because DG can generate electricity with the renewable source rather than fossil fuel and, accepted through many countries due to reduction in gasses emission is primary criteria that lead for DGs implementation. Provided peak load demand, minimizes current branch loadings, voltage profile and reduces losses can be improving with better placement and sizing of DG [3]. Allocation and sizing of DG power in an inappropriate way toward the distribution network leads to power quality issues, increasing power losses, unstable power system, and rising operational cost [4]. In most research have an objective to reduce losses in the system because the reduction in losses leads to reduction in the total cost.

Power system management has been facing major changing in the power generation sector during the past decades. Power system company must try to find the best way and solution to provide energy which is sufficient for the customer and avoid any unwanted problems in power system such as losses in the system, voltage stability and total harmonic distortion. One of the real matters found with the DG is system stability because of the interaction amongst generators and load characteristic. The increment of load or vice versa, the voltage profile drops below tolerable operating limit along with distribution feeders. Hence, the power generating station is work simultaneously, but when load increases more and more, all generating stations cannot bear the loads, and total blackout happens. Load in the distribution system affect the DGs planning significantly for the optimal placement and sizing of DG, and generally, a constant power load model is assumed in most studies [5].

Consequently, the meeting of small generation has growth and cause the rise of demand in DG utilization. The existence of DGs in the distribution system may result in some advantages such as improved power quality, voltage stability and reduction of the system, but the inappropriate installation of DGs with improper design could either cause positive and negative impact. However, it must be depending on the operational characteristic of the DGs and the criteria of the distribution network. Therefore, optimal placement and optimal of DGs is significant to be investigated for a reliable power system [6-7].

Furthermore, there is more optimization technique used in the optimal placement of DG. In [8], the researcher has investigated to reduce operation cost and decide the capacity and location of DGs in the grid by various optimization techniques. GSA has discovered better answers with fewer cost, although it used more time to stimulate the results. Moreover, the results found by GSA, in most cases, provide better results and, in all cases, [9]. In [10-12], Particle Swarm Optimization (PSO) heuristic method has been proposing to obtain the best size and best allocation for the insertion of DG within the distribution networks for active power compensation of reduction in actual power losses and enhancement in voltage profile. The whole absolute power loss reduction in the distribution system with active compensation depends on the planning of DG for maximizing the power system performance. However, in practice, the pleasant place or sizing

\footnotetext{
*Corresponding Author
} 
will not always be possible because many constraints, i.e. due to size, may not be to be had inside the marketplace.

In another paper, the authors in [13] have presented a new optimization technique for defining optimal sizing and allocation of DG in a distribution system that was the improved gravitational search algorithm (IGSA). Its performance is compared with other heuristic methods such as PSO and GSA for optimal placement and sizing. The resulted has shown that the IGSA performs better than PSO and GSA by provided the best fitness value and the fastest average elapsed time. However, the authors do not consider the load variation environment to promote a significant losses measurement in the results reporting. In the majority of the literature, the size of DG has been decided as the DG size at the whole penetration level. However, due to the volatility of DG source like solar, the real size will be higher than the defined size at the whole penetration level [14].

Generally, the DG placement problem solves with a predefined DG number and sizes that might result in many small DGs. However, a better solution could be reached with a minimum number of DGs, cutting installation and maintenance costs. But, in the time perspective of a day, a month or a year, the active and reactive load values may experience severe changes. The operator must consider these variants. Detecting the most sensitive buses concerning the base case may not be sufficient to evaluate voltage stability margin(VSM) enhancement strongly affected by load increase that might change the system stability status. Therefore, considering the load fluctuations, a fixed size for the DG cannot guarantee the optimal power losses in the system [15-16].

Thus, in this study, different to the load variation adjustment analysis, the investigation is made in a 33-bus radial distribution system while following a similar algorithm technique. The IGSA performance compares with particle swarm optimization (PSO) and gravitational search algorithm (GSA) with six case studies. The result illustrated the losses minimization, average THDV and voltage deviation in the distribution system when load variation was considering, and the efficiency of the proposed technique in minimizing the total losses and improve the voltage deviation - the arrangement of the paper present in the following structure. Section II shows the problem formulation and limitation of the DG placement and sizing. The proposed algorithms have explained in Section III, while Section IV presents the results and discussion. Lastly, Section $\mathrm{V}$ concludes the finding of the study.

\section{PROBLEM Formulation}

A multi-objective optimization problem is created as a constrained non-linear integer optimization problem for solving the optimal DG placement and sizing in a distribution system. The objective is to minimize the total power loss, the average THDv and the voltage deviation. The fitness function of the optimization problem is given by.

$F_{\text {min }}=\sum \alpha\left(P_{L O S S}\right)+\beta\left(V_{d e v}\right)+\gamma\left(T H D_{V}\right)$

Where $\mathrm{F}$ is the fitness function, $\mathrm{P}$ loss is the total power loss $(\%), \mathrm{V} d e v$ is the voltage deviation (\%), and THDv is the average THD $v(\%)$ at all system busbars. At the same time, $\alpha$ is the coefficient factor for total power loss; $\beta$ is the coefficient factor for voltage deviation, and $\gamma$ is the coefficient factor for THDv.

The total real power losses are expressed by:

$P_{\text {LOSS }}=\sum_{k=1}^{n} P_{\text {loss }_{k}} k=1,2,3,4 \ldots, n$

where $\mathrm{n}$ is the number of lines. The voltage deviation is defined by:

$V_{\text {dev }}=\frac{V_{\text {iref }}-V_{i}}{V_{i}} \times 100 \%$

where $\mathrm{V}_{\text {iref }}$ is reference voltage at bus and $\mathrm{V}_{i}$ is the actual voltage at the bus. The average $\mathrm{THD}_{V}$ is defined by:

$T H D_{V}=\frac{\sum_{i=1}^{n} T H D_{V i}}{n}$

where $n$ is the number of buses.

Generally, multi-objective methods provide a set of optimal solutions. For this paper, the sum of the coefficient factor method uses to decide the relative importance of the objectives to obtain the best optimisation solution. The coefficient factor for total power loss is assumed to be 0.4 , while the average THDv and voltage deviation consider as 0.3.The coefficients are decided based on the relative importance of the objectives in order to obtain the best optimisation solution. Sum of the weights must be equal to 1 in weighted multi objective problem formulation.

\section{A. Constraints}

1) Equality constraints: The load flow constraints are equal to the real and reactive power flow constraints, respectively, as given below [17]:

$P_{G}+P D G_{i}=P_{L O S S}+P D_{i}$

$Q_{G}+Q D G_{i}=Q_{L O S S}+Q D_{i}$

\section{2) Inequality Constraints}

Power Generation Limit [11].

$P_{D G_{i}}^{\min } \leq P_{D G_{i}} \leq P_{D G_{i}}^{\max }$

$Q_{D G_{i}}^{\min } \leq Q_{D G_{i}} \leq Q_{D G_{i}}^{\max }$

\section{Bus Voltage Limit [11].}

The bus voltage magnitudes are to be saved inside appropriate working limits during the optimization technique. The rms value of the bus voltage involves only the fundamental component.

$V_{\min } \leq\left|V_{i}\right| \leq V_{\max }$

Where Vmin is the lower bound of bus voltage limit, Vmax is the upper bound of the voltage limits and $|\mathrm{Vi}|$ is the root mean square (rms) value.

\section{Proposed Algorithm}

Many intelligent algorithms such as PSO, GSA, IGSA, GA, and others have applied optimal DG allocation in optimal allocating distributed generation. Optimization targets to determine the optimal placement for DG whilst they install in a 
distribution network. This technique is primarily base on population-based search techniques that practice both random variation and selection. In this paper, the IGSA proposes determining the optimal placement and sizing of DG in the distribution system. The Newton Raphson load flow algorithm from MATPOWER is integrated into this optimization technique to obtain the minimum fitness functions for the total power losses, average THDV and the voltage profile of the system. The proposed technique uses to discover the excellent answer to the trouble in this paper. The optimization techniques considered in this study are PSO, GSA and IGSA.

\section{A. Improved Gravitational Search Algorithm}

The improved gravitational search algorithm (IGSA) proposes an optimization technique that improved from the original gravitational search algorithm [13]. Therefore, GSA needs to be improved to get a better search result applied in the electric distribution network. In the GSA concept, an agent of performance is considered by their masses since all the agents attract each other by the gravity force causes a global movement of all agents toward the agent of more massive masses [9]. Exploration and exploitation are two contradictory objectives that enhance the achievement of GSA successes [9]. However, the GSA's weaknesses were: first, the best agent is still exploring the global space even it was in the best position. The second weakness was that the best agent is still exploring the global space, even at position [18]. Improved Gravitational Search Algorithm (IGSA) presented to eliminate the weakness and improve the quality of the result and achieve the fastest convergence speed and global searchability. In the proposed IGSA, the chaotic dynamic applied to improve the searching behaviour and avoid premature convergence [19-20]. The flow chart of the IGSA algorithm is shown in Fig. 1. This method is applied in the 33-bus radial distribution system considering load variation.

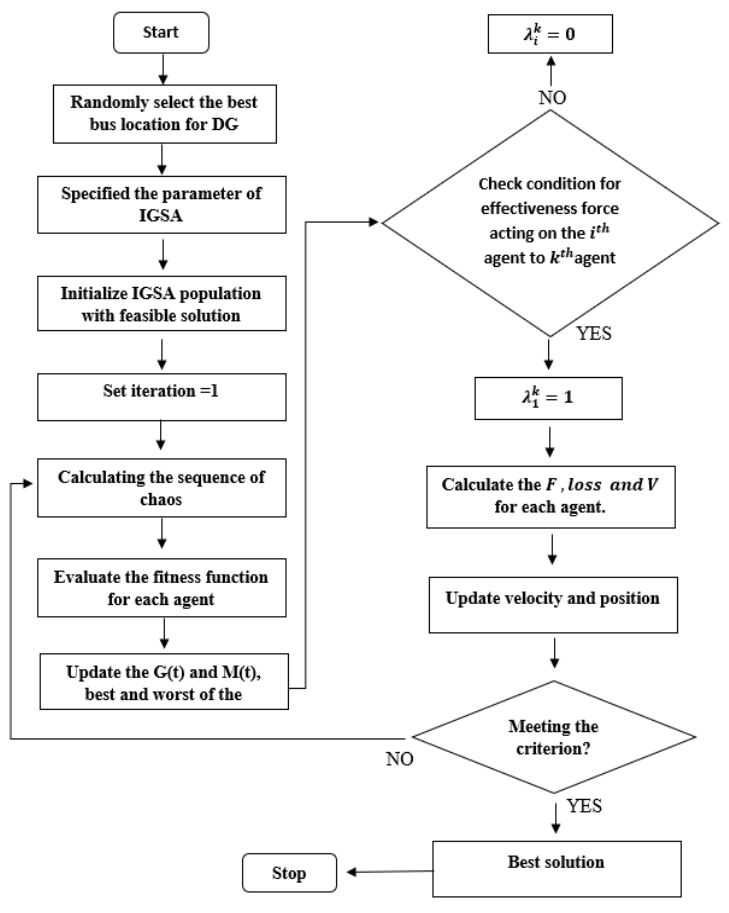

Fig. 1. IGSA Flow Chart.

\section{B. Preliminary Assumption of the DGs}

The data were obtained from bus radial system topology and used to illustrate the functionality of the proposed method to optimal placement and sizing of DG with considering load variation. The preliminary assumption of the DGs and all the parameters are set as follows:

- Voltage limit of the DGs: $0.90 \leq \mathrm{V} \leq 1.05$.

- Power Generation limit of the DGs: $30 \% \leq \mathrm{P} \leq 60 \%$ of the total connected load.

- Constant output generation with unit power factor is considered in the DG unit.

- Constant power output is modelled for all loads.

- The simulation is applied based on the changing load level.

- The installation of PVs solar units is same for each phase.

- The cost is not considered in this simulation.

- Renewable energy DG used, and only active power injected.

\section{Case Studies}

The control variable for this study was the size of DG, voltage deviation, and the location of DG. While based on the result obtained for entire real power base configuration for each variation of load and multi-objective function to minimize the losses, THD and voltage deviation, the simulation was done to find the best solution according to the case study.

The effect of the load variation is the main settings in this paper. The only supply source in the system is known as the slack bus has a constant voltage and phase angle. The maximum number of iterations is setting as 300 times for tuning process of each parameter. Six cases are considered in this paper regarding the impact of DG installed considering load variation toward power losses, average $\mathrm{THD}_{V}$ and voltage deviation. All cases implemented on the Improved Gravitational Search Algorithm (IGSA) is proposed as an optimization strategy, and its overall performance is compared with different optimization techniques. Table I show the tabulated case studies for radial distribution system with a variety of load levels, present of DGs and optimization technique used.

TABLE I. CASE StUdies

\begin{tabular}{|c|c|c|c|c|c|c|}
\hline Case No. & \multicolumn{3}{|c|}{ Optimization Techniques } & \multicolumn{3}{|c|}{ DGs Availability } \\
\hline Case 1 (Load level 25\%) & \multirow{6}{*}{ PSO } & \multirow{6}{*}{ GSA } & \multirow{6}{*}{ IGSA } & \multirow{6}{*}{$\begin{array}{l}\text { No } \\
\text { DG }\end{array}$} & \multirow{6}{*}{$\begin{array}{l}1 \\
\mathrm{DG}\end{array}$} & \multirow{6}{*}{$\begin{array}{l}2 \\
\text { DG }\end{array}$} \\
\hline Case 2 (Load level 50\%) & & & & & & \\
\hline Case 3 (Load level 75\%) & & & & & & \\
\hline $\begin{array}{l}\text { Case } 4 \\
(\text { Load level 100\%) }\end{array}$ & & & & & & \\
\hline $\begin{array}{l}\text { Case } 5 \\
\text { (Load level 125\%) }\end{array}$ & & & & & & \\
\hline $\begin{array}{l}\text { Case } 6 \\
\text { (Load level 150\%) }\end{array}$ & & & & & & \\
\hline
\end{tabular}




\section{RESULTS AND DisCUSSION}

The heuristic method that selects in this paper for optimal placement and sizing of DGs is tested on a 33-bus. The system loads are considered as a spot load, with the entire real power for base configuration is $3.72 \mathrm{MW}, 2.3 \mathrm{MVar}$ with a real power loss of $0.203 \mathrm{MW}$ for the total connected load. The maximum iteration for the IGSA, PSO and GSA algorithm is set as 300. The supply source in this system at bus 1 is known as slack bus or reference bus with a fixed voltage and fed by a single source. The load is varying from $25 \%$ up to $150 \%$.

The foundation model of the framework has a single supply point with 33-buses and tie switches which are maintained generally open and is closed to vary circuit resistance for a reduction of losses or can be closed just during fault condition to support uninterrupted supply. The line diagram of the system is demonstrated in Fig. 2.

From the simulation of three optimization techniques, the result was obtained for the fitness function, total power losses, voltage deviation at various load level. Fig. 3 shows the convergence characteristic of among 30 simulation runs for three optimization techniques on a $100 \%$ load level with 1 DG installed in the 33-bus system. The result shows that the IGSA gives the best fitness compared to PSO and GSA according to total power losses, voltage deviation and average THD $v$.

Table II shows the base case results for power losses and the average voltage deviation for variation of load levels. By increasing the load level from $25 \%$ to $150 \%$, it shows that the power losses increased while the average deviation decreased significantly.

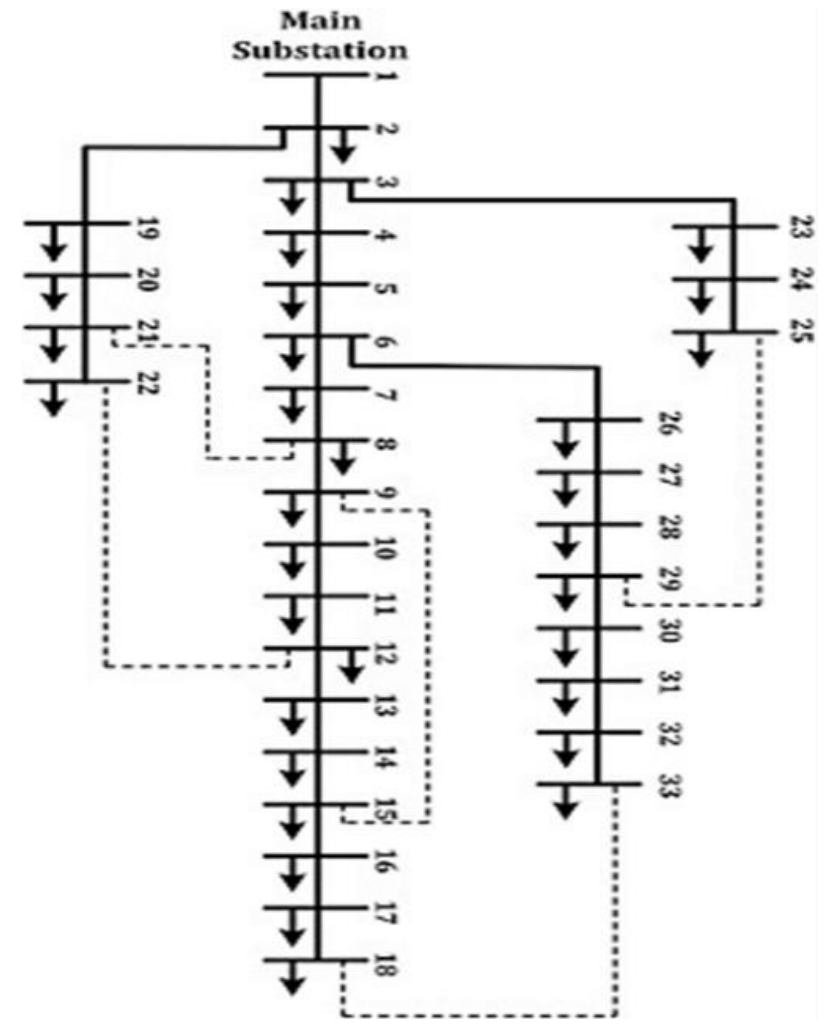

Fig. 2. IEEE 33-bus Distribution System.

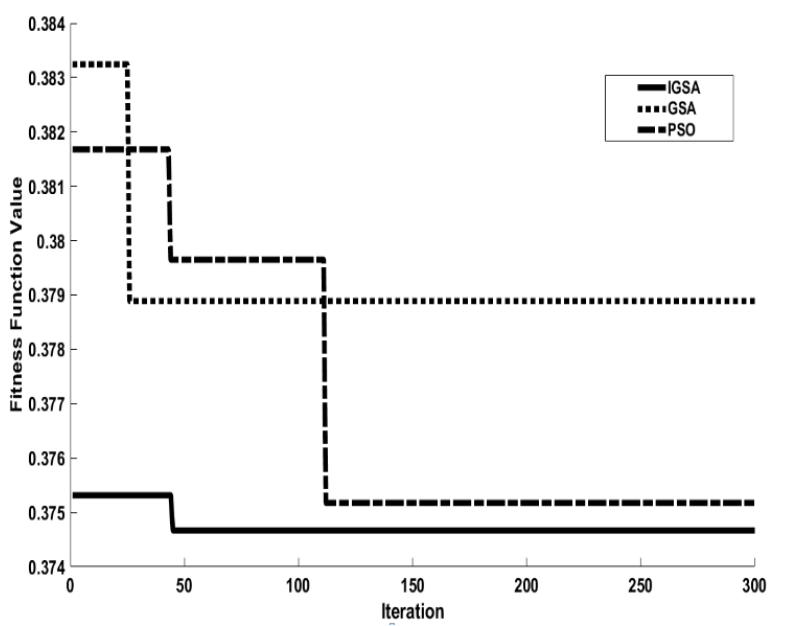

Fig. 3. Convergence Characteristic of GSA, PSO and IGSA Algorithms for 1 unit DG Installed in the 33-bus System.

TABLE II. BASE CASE For Power Losses, AND AVERAge Voltage DEVIATION FOR VARIATION OF LOAD LEVEL

\begin{tabular}{|l|l|l|l|}
\hline $\begin{array}{l}\text { Variation of Load } \\
\text { Level }\end{array}$ & \multirow{2}{*}{ DG availability } & Losses(MW) & $\begin{array}{l}\text { Average Voltage } \\
\text { Deviation }\end{array}$ \\
\hline Load 25\% & \multirow{5}{*}{ No DG } & 0.011 & 0.987758 \\
\cline { 1 - 1 } Load 50\% & & 0.047 & 0.975303 \\
\cline { 4 - 4 } Load 75\% & 0.11 & 0.962091 \\
\cline { 4 - 4 } Load 100\% & 0.203 & 0.948484 \\
\hline Load 125\% & 0.33 & 0.934182 \\
\hline Load 150\% & & 0.455 & 0.923545 \\
\hline
\end{tabular}

Table III illustrates the best fitness values of various load level, the DG availability and the optimization techniques application. From the results in Table III, it shows that the IGSA technique gives the best fitness value compared to PSO and GSA for the various load level and the DG availability. Table III also shows the optimal DG location and the optimal DG size from the best fitness function. This result shows that the optimal DG size depends on the several factors such as the DG location, the variation of load level, and the power inject in the grid.

Table IV shows the DG impact on power losses for various load level and optimization techniques application. For $25 \%$ of load level, it shows that the losses are higher compared to the base case (without DG installed in the system). Therefore, the loss reduction becomes a negative value. However, for the rest of the cases ( $50 \%$ to $150 \%$ load level), the overall results show that the losses decreased significantly compared to the losses without DG. The IGSA shows the most excellent performance of the loss reduction for all cases compared to PSO and GSA.

Table V shows the DG impact on average voltage deviation for various load level and optimization techniques application. Overall, after DG installation in the system, the average voltage deviation had improved compared before DG installation. For different load level, the performance of the three optimization techniques is balanced. Its means that IGSA, not the only technique, give excellent performance in average voltage deviation. 
TABLE III. THE BEST FITNESS VALUE OF THE DIFFERENT LOAD VARIATIONS, THE DG AVAILABILITY AND THE OPTIMIZATION TECHNIQUES

\begin{tabular}{|c|c|c|c|c|c|}
\hline $\begin{array}{l}\text { Variatio } \\
\mathrm{n} \text { of } \\
\text { Load } \\
\text { Level }\end{array}$ & $\begin{array}{l}\text { DG } \\
\text { availabilit } \\
\mathrm{y}\end{array}$ & $\begin{array}{l}\text { Technique } \\
\text { s }\end{array}$ & Fitness & $\begin{array}{l}\text { DG } \\
\text { Locatio } \\
\mathrm{n}\end{array}$ & DG Size \\
\hline & & PSO & $\begin{array}{l}0.7510 \\
2\end{array}$ & 13 & 1.697 \\
\hline & $1 \mathrm{DG}$ & GSA & 0.7496 & 3 & 1.6019 \\
\hline \multirow[t]{6}{*}{$\begin{array}{l}\text { Load } \\
25 \%\end{array}$} & & IGSA & $\begin{array}{l}0.7481 \\
5\end{array}$ & 2 & 2.2676 \\
\hline & & PSO & $\begin{array}{l}0.8013 \\
5\end{array}$ & 8,16 & $\begin{array}{l}2.9909, \\
3.1858\end{array}$ \\
\hline & 2 DGs & GSA & $\begin{array}{l}0.7958 \\
4\end{array}$ & 16,19 & $1.6032,3.0142$ \\
\hline & & IGSA & $\begin{array}{l}0.7844 \\
9\end{array}$ & 30,33 & $2.9138,1.7892$ \\
\hline & & PSO & $\begin{array}{l}0.4928 \\
2\end{array}$ & 28 & 1.9779 \\
\hline & $1 \mathrm{DG}$ & GSA & $\begin{array}{l}0.4939 \\
8\end{array}$ & 2 & 2.4131 \\
\hline \multirow[t]{6}{*}{$\begin{array}{l}\text { Load } \\
50 \% \\
\end{array}$} & & IGSA & $\begin{array}{l}0.4925 \\
9\end{array}$ & 6 & 1.6006 \\
\hline & & PSO & $\begin{array}{l}0.5067 \\
6\end{array}$ & 9,20 & $3.0436,1.7591$ \\
\hline & 2 DGs & GSA & $\begin{array}{l}0.5101 \\
8\end{array}$ & 6,29 & $3.1563,2.7326$ \\
\hline & & IGSA & $\begin{array}{l}0.5060 \\
3\end{array}$ & 24,8 & $3.101,2.4787$ \\
\hline & & PSO & $\begin{array}{l}0.4102 \\
6\end{array}$ & 33 & 2.53 \\
\hline & $1 \mathrm{DG}$ & GSA & $\begin{array}{l}0.4110 \\
2 \\
\end{array}$ & 9 & 1.6022 \\
\hline \multirow[t]{6}{*}{$\begin{array}{l}\text { Load } \\
75 \% \\
\end{array}$} & & IGSA & 0.4103 & 12 & 2.5699 \\
\hline & & PSO & $\begin{array}{l}0.4250 \\
5\end{array}$ & 11,10 & $3.1852,1.8932$ \\
\hline & 2 DGs & GSA & $\begin{array}{l}0.4374 \\
1\end{array}$ & 14,15 & $2.4907,2.8596$ \\
\hline & & IGSA & $\begin{array}{l}0.4413 \\
3\end{array}$ & 27,3 & $3.0218,2.3309$ \\
\hline & & PSO & $\begin{array}{l}0.3751 \\
8\end{array}$ & 16 & 1.9704 \\
\hline & $1 \mathrm{DG}$ & GSA & $\begin{array}{l}0.3787 \\
3\end{array}$ & 16 & 3.2343 \\
\hline \multirow[t]{6}{*}{$\begin{array}{l}\text { Load } \\
100 \% \\
\end{array}$} & & IGSA & $\begin{array}{l}0.3746 \\
7 \\
\end{array}$ & 29 & 2.535 \\
\hline & & PSO & $\begin{array}{l}0.3874 \\
1 \\
\end{array}$ & 27,29 & $\begin{array}{l}.8227, \\
3.2842 \\
\end{array}$ \\
\hline & 2 DGs & GSA & $\begin{array}{l}0.3889 \\
5\end{array}$ & 26,28 & $2.6959,2.0149$ \\
\hline & & IGSA & $\begin{array}{l}0.3850 \\
9\end{array}$ & 7,16 & $3.2642,2.9789$ \\
\hline & & PSO & $\begin{array}{l}0.3591 \\
1\end{array}$ & 26 & 2.613 \\
\hline & $1 \mathrm{DG}$ & GSA & $\begin{array}{l}0.3593 \\
8\end{array}$ & 30 & 1.6179 \\
\hline \multirow[t]{6}{*}{$\begin{array}{l}\text { Load } \\
125 \% \\
\end{array}$} & & IGSA & $\begin{array}{l}.3588 \\
8 \\
\end{array}$ & 30 & 1.6025 \\
\hline & & PSO & $\begin{array}{l}0.3607 \\
9\end{array}$ & 22,16 & $2.0857,2.5866$ \\
\hline & 2 DGs & GSA & $\begin{array}{l}0.3788 \\
2\end{array}$ & 6,5 & $3.0788,2.2627$ \\
\hline & & IGSA & $\begin{array}{l}0.3511 \\
5\end{array}$ & 19,11 & $1.7974,3.0176$ \\
\hline & & PSO & $\begin{array}{l}0.3686 \\
7\end{array}$ & 4 & 3.216 \\
\hline & $1 \mathrm{DG}$ & GSA & $\begin{array}{l}0.3690 \\
7\end{array}$ & 27 & 2.9134 \\
\hline
\end{tabular}

\begin{tabular}{|l|l|l|l|l|l|}
\hline $\begin{array}{l}\text { Load } \\
\mathbf{1 5 0 \%}\end{array}$ & & IGSA & $\begin{array}{l}\mathbf{0 . 3 6 8 1} \\
\mathbf{4}\end{array}$ & 29 & 2.3019 \\
\hline & & PSO & $\begin{array}{l}0.3669 \\
9\end{array}$ & 17,6 & $2.5285,3.2116$ \\
\hline & 2 DGs & GSA & $\begin{array}{l}\mathbf{0 . 3 8 3 5} \\
\mathbf{4}\end{array}$ & 10,8 & $2.3815,2.3805$ \\
\hline & & IGSA & $\begin{array}{l}0.3638 \\
1\end{array}$ & 27,19 & $3.0054,1.7115$ \\
\hline
\end{tabular}

TABLE IV. DG IMPACT ON POWER LOSS FOR VARIATION OF LOAD LEVEL WITH THE APPLICATION OF THREE OPTIMIZATION TECHNIQUES USING THE 33BUS SYSTEM

\begin{tabular}{|c|c|c|c|c|}
\hline $\begin{array}{l}\text { Variation } \\
\text { of Load } \\
\text { Level }\end{array}$ & $\begin{array}{l}\text { DG } \\
\text { availability }\end{array}$ & Technique & $\begin{array}{l}\text { Losses } \\
\text { (MW) }\end{array}$ & $\begin{array}{l}\text { Losses } \\
\text { reduction } \\
(\%)\end{array}$ \\
\hline \multirow{6}{*}{ Load $25 \%$} & \multirow{3}{*}{$1 \mathrm{DG}$} & PSO & 0.013012 & -18.29 \\
\hline & & GSA & 0.015509 & -40.99 \\
\hline & & IGSA & 0.011094 & -0.85 \\
\hline & \multirow{3}{*}{$2 \mathrm{DGs}$} & PSO & 0.077647 & -605.88 \\
\hline & & GSA & 0.096913 & -781.03 \\
\hline & & IGSA & 0.03915 & -255.91 \\
\hline \multirow{6}{*}{ Load 50\% } & \multirow{3}{*}{$1 \mathrm{DG}$} & PSO & 0.019751 & 57.98 \\
\hline & & GSA & 0.019975 & 57.50 \\
\hline & & IGSA & 0.017331 & 63.13 \\
\hline & \multirow{3}{*}{2 DGs } & PSO & 0.049554 & -5.43 \\
\hline & & GSA & 0.071165 & -51.41 \\
\hline & & IGSA & 0.048179 & -2.51 \\
\hline \multirow{6}{*}{ Load $75 \%$} & \multirow{3}{*}{$1 \mathrm{DG}$} & PSO & 0.046412 & 57.81 \\
\hline & & GSA & 0.048765 & 55.67 \\
\hline & & IGSA & 0.043954 & 60.04 \\
\hline & \multirow{3}{*}{$2 \mathrm{DGs}$} & PSO & 0.077539 & 29.51 \\
\hline & & GSA & 0.089623 & 18.52 \\
\hline & & IGSA & 0.048416 & 55.99 \\
\hline \multirow{6}{*}{$\begin{array}{l}\text { Load } \\
100 \%\end{array}$} & \multirow{3}{*}{$1 \mathrm{DG}$} & PSO & 0.090213 & 55.56 \\
\hline & & GSA & 0.084135 & 58.55 \\
\hline & & IGSA & 0.064468 & 68.24 \\
\hline & \multirow{3}{*}{2 DGs } & PSO & 0.11946 & 41.15 \\
\hline & & GSA & 0.129783 & 36.07 \\
\hline & & IGSA & 0.118329 & 41.71 \\
\hline \multirow{6}{*}{$\begin{array}{l}\text { Load } \\
125 \%\end{array}$} & \multirow{3}{*}{$1 \mathrm{DG}$} & PSO & 0.107128 & 67.54 \\
\hline & & GSA & 0.105893 & 67.91 \\
\hline & & IGSA & 0.105438 & 68.05 \\
\hline & \multirow{3}{*}{2 DGs } & PSO & 0.135736 & 58.87 \\
\hline & & GSA & 0.158036 & 52.11 \\
\hline & & IGSA & 0.100804 & 69.45 \\
\hline \multirow{6}{*}{$\begin{array}{l}\text { Load } \\
150 \%\end{array}$} & \multirow{3}{*}{$1 \mathrm{DG}$} & PSO & 0.150441 & 66.94 \\
\hline & & GSA & 0.14558 & 68.00 \\
\hline & & IGSA & 0.142513 & 68.68 \\
\hline & \multirow{3}{*}{2 DGs } & PSO & 0.156046 & 65.70 \\
\hline & & GSA & 0.143781 & 68.40 \\
\hline & & IGSA & 0.142916 & 68.59 \\
\hline
\end{tabular}


TABLE V. DG IMPACT ON AVERAGE VOLTAGE DEVIATION FOR VARIATION OF LOAD LEVEL WITH THE APPLICATION OF THREE OPTIMIZATION TECHNIQUES USING THE 33-BUS SYSTEM

\begin{tabular}{|c|c|c|c|c|}
\hline $\begin{array}{l}\text { Load } \\
\text { Variation }\end{array}$ & $\begin{array}{l}\text { DG } \\
\text { availability }\end{array}$ & Technique & $\begin{array}{l}\text { Average } \\
\text { Voltage } \\
\text { Deviation }\end{array}$ & $\begin{array}{l}\text { Voltage } \\
\text { Deviation } \\
\text { Improvement } \\
(\%)\end{array}$ \\
\hline & & PSO & 0.989541 & 0.18 \\
\hline & $1 \mathrm{DG}$ & GSA & 0.991644 & 0.39 \\
\hline \multirow[t]{6}{*}{ Load $25 \%$} & & IGSA & 0.988804 & 0.11 \\
\hline & & PSO & 0.996333 & 0.87 \\
\hline & 2 DGs & GSA & 0.988579 & 0.08 \\
\hline & & IGSA & 0.99748 & 0.98 \\
\hline & & PSO & 0.989555 & 1.46 \\
\hline & $1 \mathrm{DG}$ & GSA & 0.997005 & 2.23 \\
\hline \multirow[t]{6}{*}{ Load $50 \%$} & & IGSA & 0.997455 & 2.27 \\
\hline & & PSO & 0.991949 & 1.71 \\
\hline & 2 DGs & GSA & 0.978855 & 0.36 \\
\hline & & IGSA & 0.991694 & 1.68 \\
\hline & & PSO & 0.990155 & 2.92 \\
\hline & $1 \mathrm{DG}$ & GSA & 0.991082 & 3.01 \\
\hline \multirow[t]{5}{*}{ Load 75\% } & & IGSA & 0.993249 & 3.24 \\
\hline & & PSO & 0.975883 & 1.43 \\
\hline & 2 DGs & GSA & 0.964536 & 0.25 \\
\hline & & IGSA & 0.994226 & 3.34 \\
\hline & & PSO & 0.981045 & 3.43 \\
\hline \multirow[t]{7}{*}{ Load $100 \%$} & $1 \mathrm{DG}$ & GSA & 0.984045 & 3.75 \\
\hline & & IGSA & 0.981877 & 3.52 \\
\hline & & PSO & 0.98877 & 4.25 \\
\hline & 2 DGs & GSA & 0.989192 & 4.29 \\
\hline & & IGSA & 0.991498 & 4.54 \\
\hline & & PSO & 0.970058 & 3.84 \\
\hline & $1 \mathrm{DG}$ & GSA & 0.972759 & 4.13 \\
\hline \multirow[t]{6}{*}{ Load $125 \%$} & & IGSA & 0.971385 & 3.98 \\
\hline & & PSO & 0.98505 & 5.45 \\
\hline & 2 DGs & GSA & 0.9797 & 4.87 \\
\hline & & IGSA & 0.987402 & 5.70 \\
\hline & & PSO & 0.961255 & 4.08 \\
\hline & $1 \mathrm{DG}$ & GSA & 0.968894 & 4.91 \\
\hline \multirow[t]{4}{*}{ Load $150 \%$} & & IGSA & 0.967659 & 4.78 \\
\hline & & PSO & 0.982023 & 6.33 \\
\hline & 2 DGs & GSA & 0.978175 & 5.92 \\
\hline & & IGSA & 0.977769 & 5.87 \\
\hline
\end{tabular}

Table VI shows the DG impacts on average THDv for various load level and the optimization techniques. From Table VI, the increment of load level, the average THDv decreased significantly. However, the increment of the DG unit in the system is not significantly increased the average THDv in the system.
TABLE VI. DG IMPACT ON AVERAGE THDV FOR VARIATION OF LOAD LEVEL WITH THE APPLICATION OF THREE OPTIMIZATION TECHNIQUES USING THE 33-BUS SYSTEM

\begin{tabular}{|c|c|c|c|}
\hline $\begin{array}{l}\text { Variation of } \\
\text { Load Level }\end{array}$ & $\begin{array}{l}\text { DG } \\
\text { availability }\end{array}$ & Technique & $\begin{array}{l}\text { Average THD } v \\
(\%)\end{array}$ \\
\hline \multirow{6}{*}{ Load $25 \%$} & \multirow{3}{*}{$1 \mathrm{DG}$} & PSO & 2.008568 \\
\hline & & GSA & 1.997636 \\
\hline & & IGSA & 1.993228 \\
\hline & \multirow{3}{*}{2 DGs } & PSO & 2.146542 \\
\hline & & GSA & 2.197424 \\
\hline & & IGSA & 2.114125 \\
\hline \multirow{6}{*}{ Load $50 \%$} & \multirow{3}{*}{$1 \mathrm{DG}$} & PSO & 0.991635 \\
\hline & & GSA & 0.997575 \\
\hline & & IGSA & 0.993167 \\
\hline & \multirow{3}{*}{2 DGs } & PSO & 1.013134 \\
\hline & & GSA & 0.994911 \\
\hline & & IGSA & 0.988376 \\
\hline \multirow{6}{*}{ Load $75 \%$} & \multirow{3}{*}{$1 \mathrm{DG}$} & PSO & 0.658226 \\
\hline & & GSA & 0.650975 \\
\hline & & IGSA & 0.644395 \\
\hline & \multirow{3}{*}{2 DGs } & PSO & 0.664912 \\
\hline & & GSA & 0.662894 \\
\hline & & IGSA & 0.654173 \\
\hline \multirow{6}{*}{ Load 100\% } & \multirow{3}{*}{$1 \mathrm{DG}$} & PSO & 0.482678 \\
\hline & & GSA & 0.485075 \\
\hline & & IGSA & 0.478678 \\
\hline & \multirow{3}{*}{2 DGs } & PSO & 0.489467 \\
\hline & & GSA & 0.49805 \\
\hline & & IGSA & 0.486432 \\
\hline \multirow{6}{*}{ Load $125 \%$} & \multirow{3}{*}{$1 \mathrm{DG}$} & PSO & 0.4043 \\
\hline & & GSA & 0.406037 \\
\hline & & IGSA & 0.403294 \\
\hline & \multirow{3}{*}{2 DGs } & PSO & 0.394798 \\
\hline & & GSA & 0.439641 \\
\hline & & IGSA & 0.393116 \\
\hline \multirow{6}{*}{ Load $150 \%$} & \multirow{3}{*}{$1 \mathrm{DG}$} & PSO & 0.403448 \\
\hline & & GSA & 0.410749 \\
\hline & & IGSA & 0.402005 \\
\hline & \multirow{3}{*}{2 DGs } & PSO & 0.407351 \\
\hline & & GSA & 0.483203 \\
\hline & & IGSA & 0.401549 \\
\hline
\end{tabular}

After observation for losses in PSO, GSA and IGSA, the voltage profile is an observer for the proposed method on 100 $\%$ load in IGSA. In Fig. 4, the simulation result showed the voltage profile for a $100 \%$ load level with IGSA, and the DG location is selected at buses 29 with 1 DG implementation. The voltage profile increases directly from base case $0.926 \mathrm{pu}$ up to 1.0038 pu after DG was optimally installed in the distribution system guide based on IGSA method results; hence, when 2 
DGs implement at the bus no. 7 and 16. The voltage profile tends to increase slightly to reference voltage magnitude within the specified limit. When two DGs are optimally installed, the voltage magnitude increased more efficiently, as shown in Fig. 4. The overall voltage profiles showed the increase in voltage magnitudes within the specified limit when the best allocation of DGs installed in the system. The comparison of the voltage profile when no DG installed with DG installed is illustrated in Fig. 4. Increasing of DG installed in the system drastically improved the voltage magnitudes but within the specified limit.

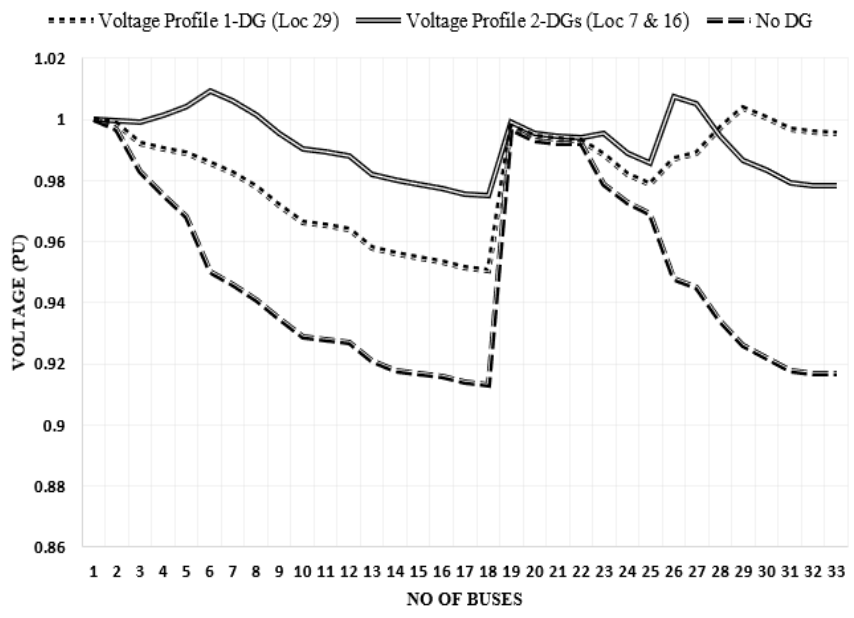

Fig. 4. IGSA Voltage Profile for 33 Bus System.

\section{CONCLUSION}

This paper has simulated the variable load in determining the optimal placement and optimal sizing of DG units using the IGSA technique. The multi-objective function was to minimize the total power, voltage deviation and THDv concerning the variation of load level. The results have shown that the proposed algorithm helps find a location to optimum total power loss of DGs in the power distribution system. The reduction of losses, voltage deviation and THDv has achieved after optimizing the DG placement and sizing. DG sizes are changing with a variety of load level and the location of DGs different for each load level. Thus, by considering the higher load level is much better for DG sizing in minimizing the losses, voltage deviation and THDv. It will reducing installation and maintenance costs as well.

\section{ACKNOWLEDGMENT}

The authors would like to thank Universiti Teknikal Malaysia Melaka for all the support given. The paper's publication sponsored by the publication support scheme under the Centre for Research and Innovation UTeM (CRIM). Special thanks also go to the Office of the Assistance ViceChancellor (Development and Facilities Management), UTeM.

\section{REFERENCES}

[1] M.Syahzad Javid, T. Ma, J. Jurasz, J. Mikulik, “ A hybrid method for scenario-based-tehcno-econimic-environmental analysis of off-grid renewable energy system", Renewable and Sustainable Energy Review, Vol. 139, 110725, 2021.
[2] T. Ackermann and T. Ackermann, "Distributed Generation: A Definition Distributed generation: a definition," vol. 7796, 2016.

[3] S. S. Rawat, "Optimum Placement and Sizing of DGs Using Analytical Method for Different Types of Loads," pp. 1-5, 2015.

[4] Rau N.S., Wan Y.H., 1994 "Optimal location of resources in distributed planning" IEEE. Trans. on Power Systems, 9(1994), No. 1, 2014-2020

[5] D. Singh and R. K. Misra, "Effect of Load Models in Distributed Generation Planning," Power Syst. IEEE Trans., vol. 22, no. 4, pp. 2204-2212, 2007.

[6] M. Abdel-Salam, M. T. El-Mohandes and L. Mahmoud, "A PSO-based Multi-objective Method for Optimal Weight Factors, Placement and Sizing of Multiple DG Units in a Distribution System," 2019 21st International Middle East Power Systems Conference (MEPCON), Cairo, Egypt, 2019, pp. 914-920, doi: 10.1109/MEPCON47431.2019.9008211.

[7] R. B. Magadum and D. B. Kulkarni, "Optimal Location and Sizing of Multiple DG for Efficient Operation of Power System," 2018 4th International Conference on Electrical Energy Systems (ICEES), Chennai, 2018, pp. 696-699, doi: 10.1109/ICEES.2018.8442393.

[8] P. Alinezhad, O. Z. Bakhoda, and M. B. Menhaj, "Optimal DG placement and capacity allocation using intelligent algorithms," 4th Iran. Jt. Congr. Fuzzy Intell. Syst. CFIS 2015, 2016.

[9] E. Rashedi, H. Nezamabadi-pour, and S. Saryazdi, "GSA: A Gravitational Search Algorithm," Inf. Sci. (NY)., vol. 179, no. 13, pp. 2232-2248, 2009.

[10] S. Kansal, B. B. R. Sai, B. Tyagi, and V. Kumar, "Optimal placement of distributed generation in distribution networks," Int. J. Eng. Sci. Technol.,vol. 3, no. 3, pp. 47-55, 2011.

[11] J. Kennedy, R. Eberhart, "Particle Swarm Optimization", IEEE,1995, PP.1942.

[12] M. R. Ab Ghani, C. K. Gan, and I. J. Hasan, "Optimum Distributed Generation Allocation Using PSO to Reduce Losses and Voltage Improvement," 3rd IET Int. Conf. Clean Energy Technol. 2014, pp. 29 (6), 2014.

[13] A. F. A. Kadir, A. Mohamed, H. Shareef, A. A. Ibrahim, T., Khatib, and S.Energy, "An improved gravitational search algorithm for optimal placement and sizing of renewable distributed generation units in a distribution system for power quality enhancement," J. Renew. Sustain. Energy, vol. 6, no. 3, pp. 1-17, 2014.

[14] Barik, Soumyabrata, and Debapriya Das. "Determining the sizes of renewable DGs considering seasonal variation of generation and load and their impact on system load growth." IET Renewable Power Generation 12.10 (2017): 1101-1110.

[15] Essallah, Sirine, Adel Khedher, and Adel Bouallegue. "Integration of distributed generation in electrical grid: Optimal placement and sizing under different load conditions." Computers \& Electrical Engineering 79 (2019): 106461.

[16] Peyman Karimyan, G.B. Gharehpetian, M. Abedi, A. Gavili, "Long term scheduling for optimal allocation and sizing of DG unit considering load variations and DG type",International Journal of Electrical Power \& Energy Systems, Volume 54,2014,Pages 277-287.

[17] H. N. Niri and A. Jalili, "Optimal placement of distributed generation in a power system by modified gravitational search algorithm," vol. 4, no. 1, pp. 30-38, 2016.

[18] A.A. Ibrahim, A. Mohamad, and A. Shareef, " A novel quantuminspired the binary gravitational search algorithm to obtain optimal power quality monitor placement," J. Appl.Sci 12,pp. 882-830, 2012.

[19] M. Eslami et al., “ An efficient particle swarm optimization technique with the chaotic sequence for optimal tuning and placement of PSS in power system," Electr. Power Energy System. 43, pp. 1467-1478, 2012.

[20] Lazzús, J. A., Vega-Jorquera, P., López-Caraballo, C. H., Palma-Chilla, L., \& Salfate, I., "Parameter estimation of a generalized Lotka-Volterra system using a modified PSO algorithm.” Applied Soft Computing, 96, 106606, pp.1-7, 2020. 